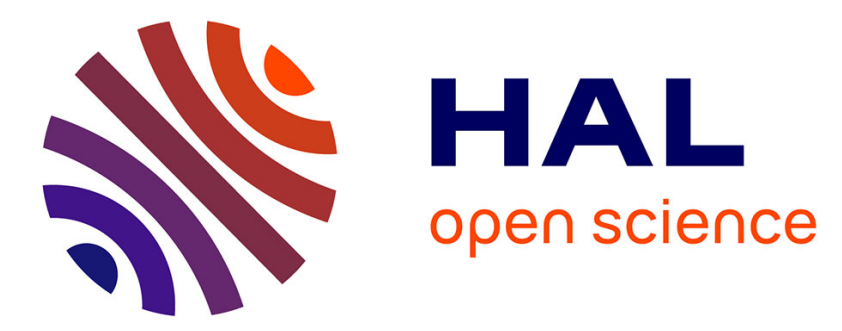

\title{
The Future of Maintenance Within Industry 4.0: An Empirical Research in Manufacturing
}

\author{
Irene Roda, Marco Macchi, Luca Fumagalli
}

\section{To cite this version:}

Irene Roda, Marco Macchi, Luca Fumagalli. The Future of Maintenance Within Industry 4.0: An Empirical Research in Manufacturing. IFIP International Conference on Advances in Production Management Systems (APMS), Aug 2018, Seoul, South Korea. pp.39-46, 10.1007/978-3-319-997070_6. hal-02177847

\author{
HAL Id: hal-02177847 \\ https://hal.inria.fr/hal-02177847
}

Submitted on 9 Jul 2019

HAL is a multi-disciplinary open access archive for the deposit and dissemination of scientific research documents, whether they are published or not. The documents may come from teaching and research institutions in France or abroad, or from public or private research centers.
L'archive ouverte pluridisciplinaire HAL, est destinée au dépôt et à la diffusion de documents scientifiques de niveau recherche, publiés ou non, émanant des établissements d'enseignement et de recherche français ou étrangers, des laboratoires publics ou privés. 


\title{
The future of Maintenance within Industry 4.0: an empirical research in manufacturing
}

\author{
I. Roda ${ }^{1}$, M. Macchi ${ }^{1}$, L. Fumagalli ${ }^{1}$ \\ ${ }^{1}$ Department of Management, Economics and Industrial Engineering, Politecnico di Milano, \\ Milano, Italy \\ irene.roda@polimi.it
}

\begin{abstract}
The recent advances in digital technologies are revolutionizing the industrial landscape. Maintenance is one of the functions that may benefit from the opportunities that emerge with the digital transformation of industrial processes. Nevertheless, until now very few research papers investigated on what digitalized manufacturing entails for maintenance organizations along both technical and social dimensions. The aim of this paper is to investigate the vision of the future of Maintenance within the industry 4.0 and to show empirical evidence on how manufacturing companies are approaching the digital transformation process of maintenance. An empirical investigation was developed through multiple casestudy involving nine manufacturing companies in Italy. Findings emerge about the main perceived challenges by companies for the success of digital transformation of maintenance as well as the technological and organizational mechanisms that are used in ongoing innovative Maintenance projects.
\end{abstract}

Keywords: Maintenance, Digital Transformation, Manufacturing, Industry 4.0.

\section{Introduction}

In the current time, looking at manufacturing, digital transformation is affecting firms' strategy, its offerings, the IT infrastructure, the way to collaborate with partners, its organizational structure, overall process organization, and core competences, as well as the overall company culture [1]. Maintenance is a relevant function for the implementation of Industry 4.0-like solutions [2], [3] and predictive maintenance and its application in machine health prognosis are popular topics in the Industry 4.0-based CPS literature [4], [5]. Nevertheless, on one hand, it is notable that in both scientific and business literature on digitalised manufacturing, maintenance is barely considered, or is perceived narrowly, with its scope confined mainly to predictive maintenance and maintenance services [3], [6]. On the other hand, maintenance research [7], [8] has primarily approached digitalised manufacturing focusing on technical advancements.

This paper is founded on the idea that digitization requires to master both technology and organization, in order to build a Smart Maintenance system. The main objective is to investigate how maintenance may benefit from the opportunities that emerge with 
the digital transformation of industrial processes in accordance with the vision of Industry 4.0. A multiple case study was carried on, involving twenty managers (both technical (production and maintenance) and ICT managers) from nine companies in Italy. The findings allow: i) investigating the visions about the future maintenance of industrial plants, and ii) showing empirical evidences on how manufacturing companies are approaching the digital transformation process of maintenance from technological and organizational perspectives.

The paper is organized as follows. Section 2 describes the scientific background of the research. Section 3 discussed the methodology that has been used. Section 4 reports the cross case study findings that are then discussed in Section 5. Section 6 is dedicated to conclusions.

\section{Scientific Background}

Scientific literature about the evolution of maintenance alongside the development of the communication and information technologies has grown since early 2000. Past concepts such as e-maintenance and Intelligent Maintenance Systems [8], have recently been enhanced by Industry 4.0 and the related key enabling technologies (Internet of Things, Cyber Physical Systems, etc.). Topics such as Condition-Based Maintenance and PHM are now under the scientific literature attention [5], [9], [10]. Nevertheless, in the existing literature there is a lack of understanding of what the realisation of digitalised manufacturing entails for maintenance organisations along both hard (technical) and soft (social) dimensions [3], [11].

In their recent paper [3], the authors clearly discuss the existing research gap between the expectations on digitalised manufacturing and the future role of maintenance. By addressing this gap, the authors implemented an empirical Delphi-based scenario planning study, identifying projections about potential changes of the internal and external environment for maintenance organisations by 2030 . They identified eight probable scenarios describing the most probable future for maintenance organisations in digitalised manufacturing, as well as three wildcard scenarios (i.e. future events that are less likely to occur but could potentially have substantial impact on maintenance organisations). In detail, according to the authors, eight dominant themes are highly likely to influence maintenance organisations, which are: i) data analytics, ii) interoperable information systems, iii) big data management, iv) emphasis on education and training, v) fact-based maintenance planning, vi) new smart work procedures, vii) maintenance planning with a systems perspective, and viii) stronger environmental legislation and standards. Regarding the wildcard scenarios, the relevant themes identified are: i) maintenance department, ii) digital networks, and iii) maintenance in social debate. As stated by the authors, their study provides guidance for further research and leaves margin for extending the geographic scope.

Based on such considerations, this research aims at verifying the identified scenarios by collecting opinions from experts of manufacturing companies in Italy, studying both their vision on the future role of maintenance within Industry 4.0 and how their companies are actually implementing the digital transformation process of maintenance 
considering both the organizational and technological dimensions. With respect to [3], this study not only involves maintenance experts but also Information \& Communication Technology (ICT) and digitalization responsible in the companies.

\section{$3 \quad$ Methodology}

In this research, a multiple case study was developed. It allowed showing empirical evidences on how companies are approaching the digital transformation process of maintenance. In particular, nine companies have been selected from multiple industrial sectors. Within the identified panel, interviews were conducted to gather the opinions of various experts in each company, belonging both to the ICT area, and to the Operations and Maintenance area. In all, twenty experts were interviewed. Table 1 shows the panel of companies that was selected for this study.

Table 1. Case study: panel of involved companies

\begin{tabular}{|c|c|c|}
\hline Company & Sector & Interviewees \\
\hline A & Steel & $\begin{array}{l}\text { - Maintenance manager, } \\
\text { - Maintenance Engineering Director } \\
\text { - R\&D Director } \\
\end{array}$ \\
\hline $\mathrm{B}$ & Turbines & - Technical service Director \\
\hline $\mathrm{C}$ & Steel & $\begin{array}{l}\text { - Production Director } \\
\text { - ICT Director } \\
\text { - Maintenance Director } \\
\end{array}$ \\
\hline $\mathrm{D}$ & Tyres & - Global Maintenance Manager \\
\hline $\mathrm{E}$ & Oil\&Gas & $\begin{array}{l}\text { - IT Digital Innovation \& IT Operation corporate Director } \\
\text { - Offshore Drilling and Digitalization R\&D Director } \\
\text { - Maintenance Director Offshore } \\
\end{array}$ \\
\hline $\mathrm{F}$ & $\begin{array}{l}\text { Industrial } \\
\text { gases }\end{array}$ & $\begin{array}{l}\text { - Production Plants Director } \\
\text { - Plant Director }\end{array}$ \\
\hline G & Oil\&Gas & $\begin{array}{l}\text { - Digital projects Coordinator } \\
\text { - Maintenance Director } \\
\text { - Inspections Director }\end{array}$ \\
\hline $\mathrm{H}$ & Steel & $\begin{array}{l}\text { - Technical Function and Maintenance Director } \\
\text { - R\&D and data science Director } \\
\text { - Maintenance Engineering Director }\end{array}$ \\
\hline I & Mechanical & $\begin{array}{l}\text { - Technical Functions Director } \\
\text { - ICT Director }\end{array}$ \\
\hline
\end{tabular}

\section{Cross case study findings analysis}

Based on the undertaken analysis and coding of the interviews with the experts, the findings are presented hereafter through a cross-cases synthesis. In particular, in the first sub-section, findings about the vision of the future of Maintenance in the Industry 4.0, including expected benefits and foreseen barriers are reported. The second sub- 
section shows evidences on how companies are approaching the ongoing transformation process looking at both technological and organizational issues.

\subsection{Vision, expected benefits and barriers}

Based on the considerations gathered about the future of Maintenance from the experts involved in the case study, data analysis and the definition of the role of the human factor are considered two fundamental issues referring to the future of Maintenance.

The two predominant visions are a data-centered maintenance vision and a humancentered maintenance vision. Regarding the first one, the interviewees highlighted the possibility of increasing knowledge and opening new perspectives for the company thanks to the availability and analysis of (big) data, that is also recognized as a challenge for the IT facing the management of large amounts of data (in so-called Data lakes).

The main weaknesses with this regard are the costs, which still characterize some advanced technological solutions, as well as the cost and difficulty of finding resources on the market with the necessary analytics and IT skills. Main threats of a data-centered maintenance are those linked to the exposure to the risk of cyber attacks, as well as the risk of losing contact with the physical dimension of industrial processes and assets, which leads to the need to secure the necessary competence based on engineering skills and know-how. Regarding the human-centered maintenance vision, the interviewees foresee the strength of the centrality of man, and human experience, allowing intelligence in the monitoring of the health status of the assets, as well as guaranteeing the capacity to adapt to changes (resilience). The main identified threat is represented by the potential resistance to change of people. Overall, the expected benefits of digitization of maintenance have been clearly identified by the companies interviewed, and they are the following (brackets indicate the number of companies in the panel that indicated the reference benefit, being shared in the opinion of the experts interviewed in each company):

- the possibility of improving the ability to predict the dynamics of production processes and / or asset degradation processes ( 9 companies),

- (consequently) the possibility of improving the reliability of plants (7 companies),

- the possibility of improving knowledge of production processes and / or asset degradation processes (6 companies),

- the possibility of improving efficiency in the use of maintenance resources (6 companies);

- the possibility of improving the safety of people (6 companies).

In addition to the benefits of digitization of maintenance, the findings of the case study reveal interesting evidence regarding the elements identified as main barriers, or rather, factors that can slow down the process of digital transformation of maintenance.

The most commonly indicated barriers by the experts interviewed are the following:

- lack of corporate culture towards decisions based on data / evidence (7 companies),

- lack of a structured collaboration in the digital network for a sustainable long-term project of digital transformation of maintenance (6 companies). 
Interestingly, the two main barriers identified by respondents are of organizational nature. The first barrier highlights elements of the organization that are strongly impacted by the digital transformation: the corporate culture, in the first place, and the decisionmaking process, in second place. The second barrier concerns the entire network of actors involved in the value chain for the design of future Maintenance solutions (endusers, OEMs, technology suppliers, service providers, ...). The emerging of this barrier is symptomatic of the importance that the respondents give to a structured collaboration for the development of future Maintenance projects. Respondents with responsibility in Operations and Maintenance, in addition to the two barriers mentioned above, identify an additional important organizational barrier, which is:

- the lack of skills and abilities of operators on digital technologies (4 O\&M responsibles and 2 ICT responsibles).

The same maintenance managers or plant engineering managers then identify a further critical aspect that can slow down the digital transformation process of maintenance that is an economic-financial barrier, i.e.:

- the intrinsic difficulty in establishing the payback of an investment for the digital transformation of maintenance (7 companies).

Beyond the payback, some respondents underline the uncertainty on the impacts in the Total Cost of Ownership (TCO) of new equipment / instruments purchased to upgrade the infrastructure according to the paradigm of Industry 4.0.

The only technological barriers perceived as critical among the companies interviewed are:

- the lack of widespread standard solutions for new technologies,

- the potential lack of guarantees from current Cyber Security technologies on the complete effectiveness in data protection (experts from 4 companies agree on these elements).

\subsection{Implementation mechanisms of the digital transformation of maintenance}

The companies involved in the case study are companies that have undertaken a process of digital transformation of industrial processes, including a development program that involves maintenance. This aspect allowed the investigation on how they are approaching the digital transformation process of maintenance considering on-going projects. In particular, in next sub-sections the main findings that have been collected looking at organizational and technological issues, are presented.

\section{Organizational issues}

The case study allowed investigating on the organizational aspects in the development of a Maintenance project under the Industry 4.0 paradigm. It was interesting to discover 
that, to undertake and conduct the digital transformation process of maintenance, most of the companies in the panel introduced new organizational solutions.

In particular, the focus has been placed on team-working as a primary organizational lever. With different levels of formalization, depending on the case, the tendency is to promote inter-functional teams, with multiple skills, combining the know-how of different business functions, selected according to the project objectives. The most common solution (seven companies) among the companies in the panel was the creation of inter-functional teams that involve, first of all, operations, maintenance and ICT management, while other solutions, if when the technical complexity requires it, include integration with other functions, such as Human Resources management, process technologies and plant automation.

Another organizational solution implemented by some companies interviewed concerns the introduction into the organizational structure of new roles and professional figures that bring complementary skills to those inherent to industrial processes, such as data scientists or experts of Industry 4.0. In some cases, the organizational position of the Chief Digital (Transformation) Officer is explicitly defined or, more generally, the focus is on the involvement of an innovation manager.

\section{Technological issues}

The case study implementation also allowed investigating the role of the enabling technologies of Industry 4.0 for the digitization of maintenance.

Interestingly, what clearly emerges is how modeling and simulation are recognized a fundamental role for the future of maintenance ( 7 companies have indicated these technologies as relevant). Due to their intrinsic characteristics, these technologies let presume, in the future, the importance of defining the so-called digital twin of asset systems to support the maintenance processes. Other technology to which value is recognized for supporting the decision-making processes are the tools for monitoring conditions ( 8 companies). Sensors are also recognized (by 7 companies) as important infrastructural technology, without which it is not possible to undertake a real process of digital transformation. Technological solutions such as smart devices (eg smart watches) and, more generally, portable devices (such as tablets) are also recognized (by 6 companies) as important tools with an informative function, in particular, as support for operator in the shop floor. Augmented reality, is seen as an evolved technology (from 5 companies) which, however, will not be adopted in the near future. The Cloud, has received rather mixed opinions, with reference to the related problems of Cyber Security. In some cases, the Virtual reality is also mentioned for predominantly formative purposes, i.e. for training of operational staff, especially for plants located in countries where technical maintenance culture is not advanced. Finally, Artificial Intelligence (AI) and Business Intelligence (BI) analytics are two other technologies recognized as important (respectively by 5 companies) to provide an infrastructure to create decision support tools. Alongside modeling and simulation technologies, they can contribute their data analytics functions to the digital twin of the asset system. 


\section{$5 \quad$ Discussion of findings}

Referring back to the eight dominant themes that [3] identified in their work as highly likely to influence maintenance organisations, all of them came forth from the crosscase study findings analysis. Some of them appear to be more relevant than others, two of the three wildcard scenarios have actually emerged as relevant. Summarising, the relevance and centrality of data for the future of Maintenance that is identified in the study by [3], clearly emerged from the case study findings analysis as well. The challenge given by the achievement of high quality maintenance data and developing maintenance management systems that automatically transform big data into decision support is identified both in [3] and in the case study. In this study, the challenge is identified not only for Maintenance but also for the ICT function, facing the need of managing large amounts of data (in so-called Data lakes). From the case study, the role of the human factor as a core issue together with data for the future of Maintenance is confirmed. Not only, the need to keep up with technological development emerges but also, the need to secure the necessary engineering competence not to lose contact with the physical assets and the required technical knowledge to support decision-making.

Regarding the wildcard scenarios identified by [3], two of the three relevant themes identified, strongly emerged from the case studies, and they are: i) maintenance department and ii) digital networks.

Finally, one challenge that emerged from the case study implementation and that is not underlined in the study by [3] is the intrinsic difficulty in establishing the payback of an investment for the digitization of maintenance. Beyond the payback, some respondents underline the uncertainty on the impacts in the Total Cost of Ownership of new equipment / instruments purchased to upgrade the infrastructure according to the paradigm of Industry 4.0. This gives an evidence on the need for methodologies to be able to evaluate the cost-effectiveness of the new solutions.

\section{Conclusions}

This paper provides insights about the future role of Maintenance in the manufacturing sector within Industry 4.0. In particular, the objective is the investigation of how Maintenance may benefit from the opportunities that emerge with the ongoing digital transformation of industrial processes. To this aim, a case study involving nine companies and twenty experts belonging to both technical functions (operations and maintenance) and to ICT/innovation functions were involved. First of all, the research allowed identifying the main issues that will characterize the Maintenance in the future under the Industry4.0 paradigm. The two core elements for the success of the digitalization of maintenance processes emerged and they are data and the human factor. Secondly, the research aimed at detecting empirical evidences on how manufacturing companies are actually approaching the digital transformation process of maintenance. Even in this case, relevant issues emerge not only of technological type but also organizational ones.

The development of further research (e.g. more case studies, a Delphi analysis etc.) would help better capturing and studying the alignment of business and technology 
goals in the target domain. The work complements the study by [3] in different ways. It enlarges the analysis to the Italian industrial context, it collects opinions not only from maintenance experts but also from experts with responsibility roles for the digitalization process and finally, it studies ongoing innovative maintenance projects. The case study was also developed more recently, starting from the second half of 2017 until beginning of 2018 .

\section{Acknowledgments}

The research work was performed within the scope of TeSeM Observatory (www.tesem.net).

\section{References}

1. Pflaum A. A. and Michahelles F.: The IoT and Digital Transformation : Toward the DataDriven Enterprise. IEEE Pervasive Comput.,87-91 (2018).

2. Macchi M., Roda I., and Fumagalli L.: On the Advancement of Maintenance Management Towards Smart Maintenance in Manufacturing. IFIP Advances in Information and Communication Technology, 513, 383-390 (2017).

3. Bokrantz J., Skoogh A., Berlin C., Stahre J.: Maintenance in digitalised manufacturing: Delphi-based scenarios for 2030. Int. J. Prod. Econ., 191, 154-169 (2017).

4. Zheng P., Wang H., Sang Z., Zhong R. Y., Liu Y., Liu C., Mubarok K., Yu S., and Xu X.: Smart manufacturing systems for Industry 4.0: Conceptual framework, scenarios, and future perspectives. Front. Mech. Eng., 13(2), 1-14 (2018).

5. Lee J., Ghaffari M., Elmeligy S.: Self-maintenance and engineering immune systems: Towards smarter machines and manufacturing systems. Annu. Rev. Control, 35(1), 11-122, (2011).

6. Liao Y., Deschamps F., Loures E. de F. R., and Ramos L. F. P.: Past, present and future of Industry 4.0 - a systematic literature review and research agenda proposal. Int. J. Prod. Res., 55(12), 3609-3629 (2017).

7. Alaswad S. and Xiang Y.: A review on condition-based maintenance optimization models for stochastically deteriorating system. Reliab. Eng. Syst. Saf., 157, 54-63 (2017).

8. Guillén A. J., Crespo A., Macchi M., Gómez J.: On the role of Prognostics and Health Management in advanced maintenance systems. Prod. Plan. Control, 27(12), 991-1004 (2016).

9. Moore W. J. and Starr a. G.: An intelligent maintenance system for continuous cost-based prioritisation of maintenance activities. Comput. Ind., 57(6), 595-606 (2006).

10. Jardine a. K. S., Lin D., Banjevic D.: A review on machinery diagnostics and prognostics implementing condition-based maintenance. Mech. Syst. Signal Process., 20(7) 1483-1510 (2006).

11. Pellegrino J., Justiniano M., Raghunathan A.: Measurement Science Roadmap for Prognostics and Health Management for Smart Manufacturing Systems. NIST Adv. Manuf. Ser. 100(2) (2016). 